\title{
Central Nervous System Tuberculosis Subsequent to Dural Grafting
}

\author{
Galip Zihni Sanus, Taner Tanriverdi, Banu Tutunculer, Mustafa Onur Ulu, Emin Ozyurt
}

Can. J. Neurol. Sci. 2008; 35: 531-534

Despite modern diagnostic and treatment modalities, tuberculosis (TB) still remains a major worldwide health problem. Resurgence in developed countries is due mainly to infection with the human immunodeficiency virus, immigration from developing and/or underdeveloped countries, transmissions in hospitals and prisons and development of multidrug-resistant strains of TB. ${ }^{1}$ According to the estimates of World Health Organization, TB accounts for 7-8 million new cases every year and is responsible for 2.9 million deaths worldwide annually. ${ }^{2}$ Tuberculosis infection is encountered mainly in underdeveloped or developing countries, but increasing infection rate has recently been reported even in developed countries. ${ }^{3}$ As a developing country, it has been estimated that TB is increasing rather than decreasing since the 1970s in Turkey and is still a serious problem in this country. ${ }^{4}$ It has been estimated that neurological involvement of TB infection constitutes approximately $5-15 \%$ of the cases, with a high predominance in children., ${ }^{5,6}$ Central nervous system (CNS) involvement including atypical forms have been reported and reviewed extensively in the literature. ${ }^{7-9}$ The bacteria are transmitted through inhalation of aerosolized droplets and CNS involvement occurs mainly by hematogenous route. Although iatrogenic CNS infections have been reported, such as after lumbar puncture, ${ }^{10}$ there has been no report of CNS TB after allogenic dural grafting.

This report concerns allogenic dura mater graft-related lumbar and cerebellar TB in a 20-year old male who underwent on operation to correct Chiari type-I malformation in which posterior fossa decompression followed by allograft dural grafting had been performed. As far as we know, this is the first report of CNS TB following the use of allograft dura mater.

\section{Case Report}

A 20-year-old male was referred to the Neurosurgical Department, Cerrahpasa Medical Faculty, Istanbul University, for further diagnosis and treatment. The patient complained of lumbar pain radiating to both lower extremities, which was accompanied by recent headache. Physical examination disclosed nothing abnormal. However, neurological examination revealed lower extremity weakness (1/5) and neck stiffness. Medical history showed that he had an operation to correct a Chiari type-I malformation, in which posterior decompression plus C1 laminectomy and dural grafting with cadaveric allograft was performed six months prior to the admission to us (Figure 1). The postoperative period was uneventful until he developed

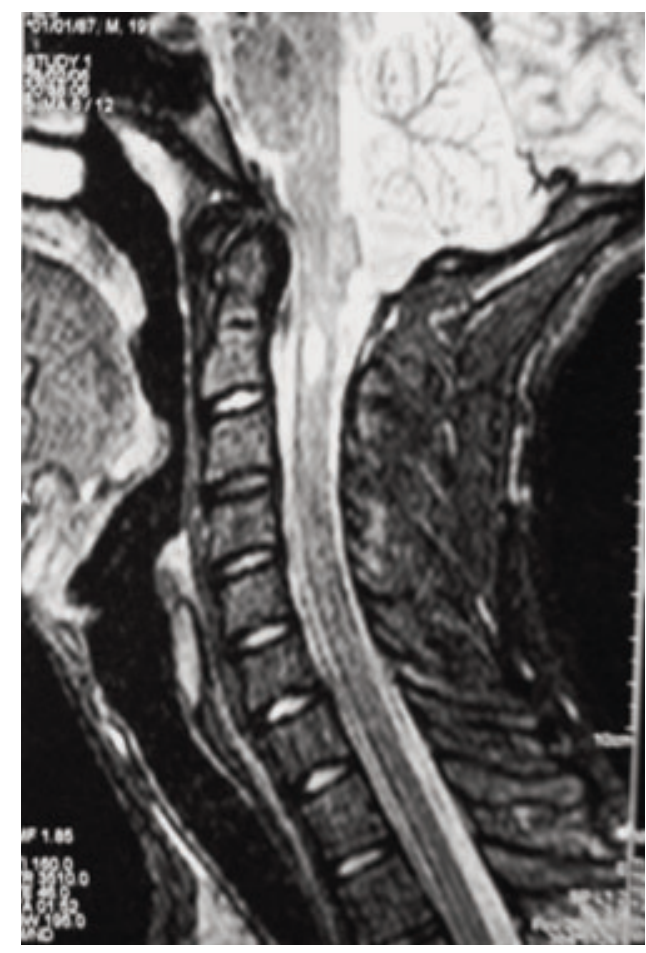

Figure 1. Sagittal T2-weighted MRI image showing Chiari type-I malformation with syrinx at C2 level.

severe headache and neck pain four months after the surgical intervention. He was evaluated by his primary neurosurgeon and radiological examination at that time disclosed the syrinx had resolved completely and so it was decided to follow the patient clinically. Two months after his last visit, he developed severe

From the Department of Neurosurgery, Istanbul University (GZS, BT, MOU, EO), Cerrahpasa Medical Faculty, Istanbul, Turkey; Department of Neurosurgery, Montreal Neurological Institute and Hospital (TT), McGill University, Montreal, Quebec, Canada.

Received November 30, 2007. Final Revisions Submitted March 8, 2008. Correspondence to: Taner Tanriverdi, Department of Neurosurgery, Montreal Neurological Institute and Hospital, 3801 rue University, suit 109, Montreal, Quebec, H3A 2B4, Canada. 


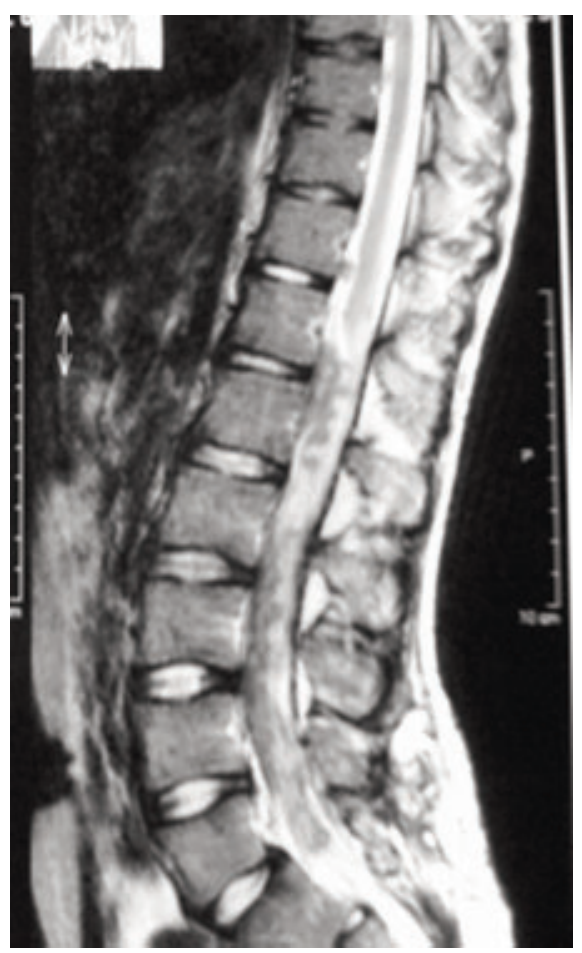

Figure 2. Sagittal T2-weighted lumbar MRI obtained six months after the surgery demonstrating widespread heterogeneous lesions extending from L1 to L4 levels.

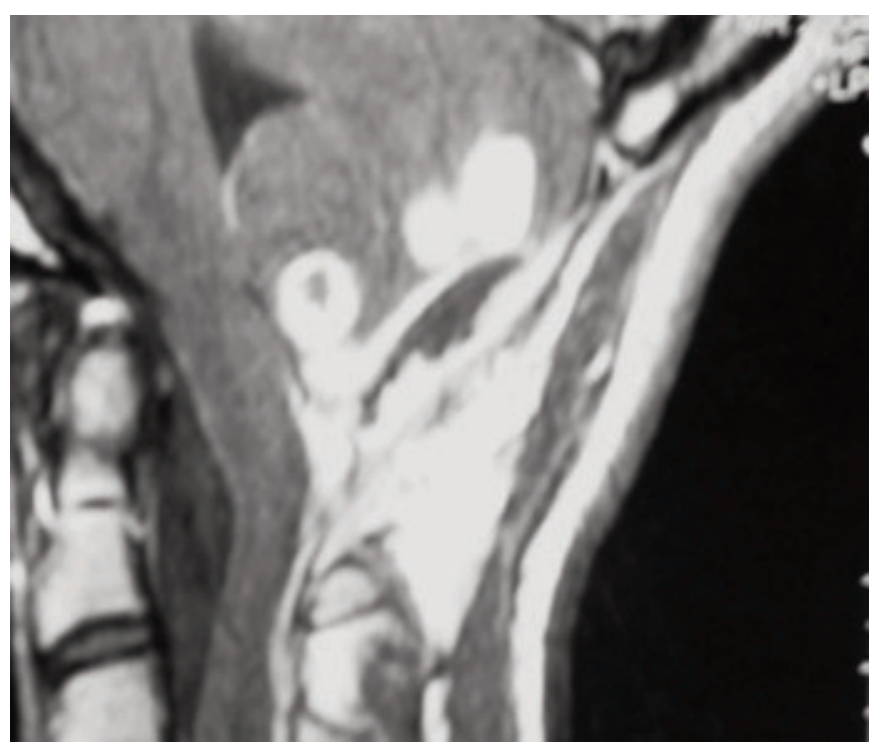

Figure 3. Sagittal T1-weighted contrasted MRI obtained at the time of patient's admission to our unit showing cranio-cervical junction in which ring enhancing lesions in the cerebellar vermis and right cerebellar hemisphere posterior inferior portion and dural enhancement and thickening extending to the cervicomedullary junction. lumbar pain radiating to left lower limb and left lower limb weakness. He was evaluated by another neurosurgeon who requested lumbar magnetic resonance imaging (MRI) which revealed widespread enhancing heterogeneous lesions in the lumbar area involving conus medullaris (Figure 2). Histopathological diagnosis from the biopsy material in the lumbar area was consistent with chronic granulomatous inflammatory reaction but culture was negative. He was then referred to us for further diagnosis and treatment. During our inpatient evaluation he had no fever and blood cell count was normal. Purified protein derivative test and chest X-ray were also normal. Repeated cranial MRI with gadolinium showed ring enhanced lesions located on cerebellar vermis and right cerebellar hemisphere. Furthermore, dural enhancement and thickening, extending to the cervicomedullary junction were remarkable (Figure 3). The patient was taken to the operation room where we removed the allograft that was placed in the first procedure and replaced it with a fascia lata autograft. The histo-pathological diagnosis revealed chronic active granulomatous inflammatory reaction (Figure 4). Culture was negative but polymerase chain reaction test showed positive DNA for Mycobacterium Tuberculosis. Antituberculous drug regimen included four drugs were initiated. Thoracic, abdominal and pelvic imaging were performed to search for systemic tuberculous foci but they showed nothing abnormal. The patient had no family history of TB and no medical history of any other significant diseases. Repeated MRI, covering cranial space and whole spine, disclosed significant improvements of the lesions six months after the initiation of antituberculous drug treatment (Figure $5 \mathrm{~A}$ and B). Last follow-up showed that headache and lumbar pain had resolved completely and neurological examination was totally normal.

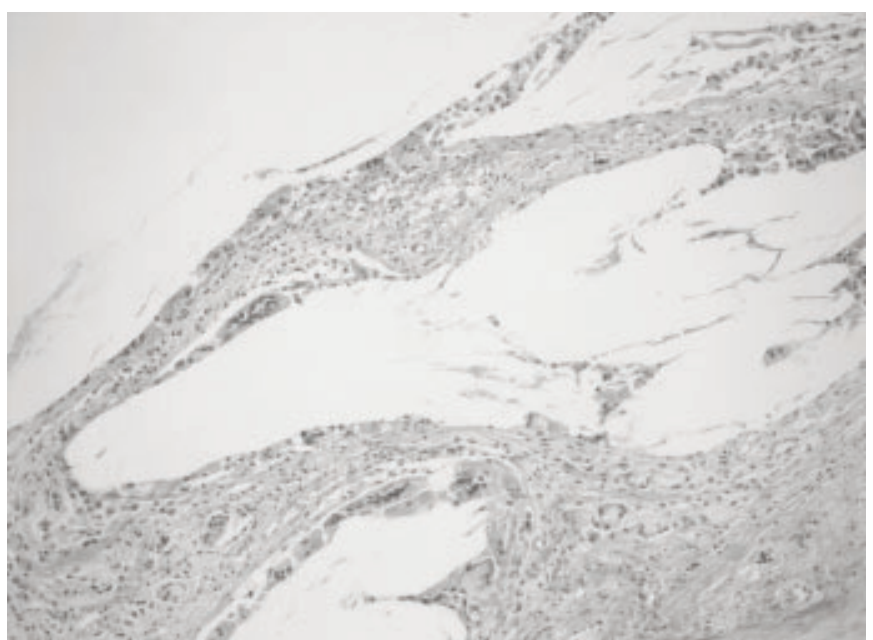

Figure 4. Histopathological diagnosis showed lymphocyte infiltration around the foreign body (allograft) which was suggestive of chronic granulomatous infection. 

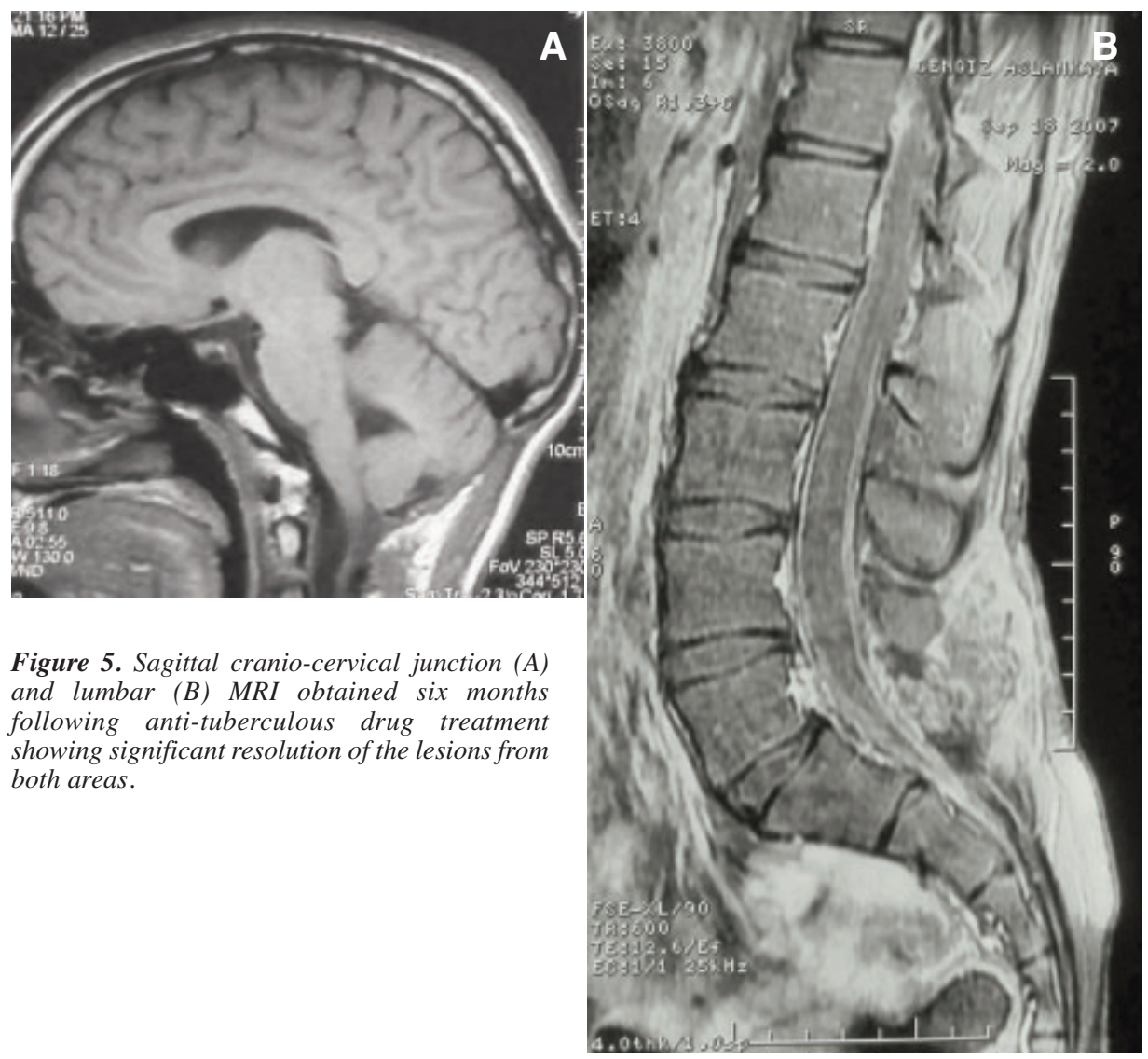

Figure 5. Sagittal cranio-cervical junction (A) and lumbar (B) MRI obtained six months following anti-tuberculous drug treatment showing significant resolution of the lesions from both areas.

\section{Discussion}

Comprehensive review of the literature did not identify any other studies reporting central nervous system TB following allogenic dural graft. Recent fatal and debilitating bacterial infections that were caused by contaminated allogenic materials have called attention to allograft materials and to bacterial infections as important complications from tissue transplantation. It has been well-documented that despite meticulously designed sterilization techniques during removal, processing and marketing of the allografts, life-threatening infectious complications from allogenic materials still exist. ${ }^{11,12}$ Bacterial infections are particularly associated with bone, tendon, cartilage, cornea, dura, heart valve, skin and pericardium. ${ }^{13}$ Apart from bacterial infections, allograft-related virus and fungal infections have also been reported. ${ }^{14-16}$ The TB infection after allogenic grafts was seen especially after bone and heart valve grafting. ${ }^{12}$ Considering the CNS, fatal complications such as prion diseases (Creutzfeldt-Jakob disease) have been reported after allogenic dural grafting ${ }^{11}$ but there have been no reports citing allogenic dural graft-related TB in the CNS. In our patient, following placement of allogenic dural graft in the surgical treatment of Chiari type-I malformation, TB infection developed in the cerebellum in an area where allogenic dural graft was placed and in the lumbar spinal cord. We think that TB may have been transmitted by the dural allograft and spread cranio-caudally. After experiencing this case, we notified the

tissue supplier. However, we were not able to get any information about the donor source. We were only informed that tissue processing includes five steps: Delipidization, a process in which lipids are removed in an ultrasonic acetone baths in order to prevent bacterial growths; Osmotic treatment, which destroys bacteria by utilizing a series of alternating hyperosmotic saline and distilled water baths. This process ruptures the cell membranes leading to killing bacteria; Oxidative treatment, which eliminates soluble proteins. Non-enveloped viruses and bacterial spores are destroyed using an oxidative treatment with hydrogen oxide; Solvent dehydration, final acetone wash removes any residual prions and enveloped viruses are destroyed. As a final step, gamma irradiation is applied in order to eliminate any microbial contamination that may result from post-allograft processing. The supplier explained that the tissue processing summarized above meets all requirements set by the U.S. FDA and American Association of Tissue Banks (AATB). ${ }^{12,17}$ Medical authorities, including the neurosurgeon who performed the first operation and placed the allograft and the hospital where the allograft was placed were notified about these potentially contaminated grafts.

We underline that complete absence of bacterial and other infectious agents is of great importance for bone or dura as presented here that are surgically implanted within the CNS which may not tolerate infections if left untreated. Our case 
indicated that although the tissue processing meets all requirements set by the FDA and AATB, the risk of infections apparently persisted and improvements in tissue banking and the handling of tissue allograft may be needed. Thus, surgeons should suspect that dural allografts may be a source of TB in recipients, especially when the infection is unusual. After fatal CNS prion disease, namely Creutzfeldt-Jakob disease (CJD), subsequent to dura mater graft was first reported in $1987,{ }^{18}$ subsequently decontamination procedures were changed and improved and are now considered to be safe. However; recent reports by the Center for Disease Control and Prevention $(\mathrm{CDC})^{11,18}$ suggested that the risk has not been eliminated and recommended that neurosurgeons should avoid using human dura mater whenever possible. Furthermore, following the first case with CJD associated with the use of tutoplast dura, ${ }^{18}$ Health Canada took action to obtain further information on the current surgical need for the use of tutoplast dura in Canada in 2002. Following this action, The Canadian Neurosurgical Society (CNSS) conducted a survey of their members and found that almost $61 \%$ of the members supported discontinuing the use of donor dura mater. ${ }^{19}$ On April 10, 2002, the use of tutoplast was suspended in Canada. The CNSS, in agreement with the CDC recommended that tutoplast should not be used as it is no longer licensed for sale in Canada and if any center has tutoplast dura, it should be placed in a secure location so that it can no longer be used and immediately inform the manufacturer or distributor who sold the devise. ${ }^{19}$

\section{CONCLUSION}

In conclusion, we believe that the actual number of infections caused by dural allografts is likely higher and underestimated since serious infections may be more likely to be reported than non-serious infections. Neurosurgeons should be aware of infectious risks of dural allografts and if the infectious agent is found to be unusual, the patient's infection is suspected to have arisen from the allograft. Tuberculosis should be included on the list of dural graft-related bacterial infections and prompt diagnosis and treatment should be initiated which prevents catastrophic results. We believe that allograft dura mater usage should be avoided as much as possible and if applicable, autografts should be used which have been said to be the cheapest and the most reliable materials.

\section{ACKNOWLEDGEMENTS}

The authors thank Fehmi Tabak, M.D., Department of Microbiology and Buge Oz, M.D., Department of Pathology, Istanbul, for studying the relevant materials and providing the results. Thanks to Salih Bilgic, M.D., Department of Neurosurgery, Vatan Hospital, Istanbul for providing the information related to previous surgery and Fusun Kobas Tanriverdi for her technical help during manuscript preparation.

T.T. is a fellow at the Department of Neurosurgery (section of Epilepsy Surgery), Montreal Neurological Institute, Montreal, Quebec, Canada and is supported by a scholarship (Mark Rayport and Shirley Ferguson Rayport Clinical Fellowship in Epilepsy Surgery) provided by Mark Rayport \& Shirley Ferguson Fund. There is no conflict of interest in this report.

\section{REFERENCES}

1. Hua SE, Clatterbuck RE, Sterin BJ, Sampath P, Rhines LD. Sarcoidosis, tuberculosis, and xanthogranuloma. In: Winn HR, Decay RG, editors. Youmans Neurological Surgery. Philadelphia: Elsevier Inc; 2004. p. 1439-47.

2. Raviglione MC, Snider DE, Kochi A. Global epidemiology of tuberculosis- morbidity and mortality of a worldwide epidemic. JAMA.1995;273:220-6.

3. Dolin PJ, Raviglione MC, Kochi A. Global tuberculosis incidence and mortality during 1990-2000. Bull WHO. 1994;72:213-20.

4. World Health Organization. Global tuberculosis control: surveillance, planning, financing. WHO Report 2006 (WHO/ CDS/TB/2006.362). Geneva: World Health Organization; p. 2006

5. Farinha NJ, Razali KA, Holzel H, Morgan G, Novelli VM. Tuberculosis of the central nervous system in children: a 20 -year survey. J Infection. 2000;41:61-8.

6. Kumar R, Pandey CK, Bose N, Sahay S. Tuberculous brain abscess: clinical presentation, pathophysiology and treatment (in children). Child's Nerv Syst. 2002;18:118-23.

7. Almeida A. Tuberculosis of the spine and spinal cord. Eur J Radiol. 2005;55:193-201.

8. Bernaerts A, Vanhoenacker FM, Parizel PM, Van Goethem JVM, van Altena R, Laridon A, et al. Tuberculosis of the central nervous system: overview of neuroradiological findings. Eur Radiol. 2003;13:1876-90.

9. Tanriverdi T, Kizilkilic O, Hanci M, Kaynar MY, Unalan H, Oz B. Atypical intradural spinal tuberculosis: report of three cases. Spinal Cord. 2003;41:403-9.

10. Torres E, Alba D, Frank A, Diez-Tejedor E. Iatrogenic meningitis due to Streptococcus salivarius following a spinal tap. Clin Infect Dis. 1993;17:525-6.

11. Brown P, Brandel JP, Preese M, Sato T. Iatrogenic CreutzfeldtJakob disease: the waning of an era. Neurology. 2006;67: 389-93.

12. Eastlund T. Bacterial infection transmitted by human tissue allograft transplantation. Cell Tissue Bank. 2006;7:147-66.

13. Wang S, Zinderman C, Wise R, Braun M. Infections and human tissue transplants: review of FDA MedWatch reports 2001-2004. Cell Tissue Bank. 2007;3:1-12.

14. Centers for disease control, prevention. Epidemiologic notes and reports transmission of HIV through bone transplantation: case report and public health recommendations. MMWR Morb Mortal Wkly Rep. 1988;37:597-9.

15. Centers for disease control, prevention. Hepatitis C virus transmission from an antibody-negative organ and tissue donorUnited States, 2000-2002. MMWR Morb Mortal Wkly Rep. 2003;52:273-6.

16. Kuehnert MJ, Clark E, Lockhart SR, Soll DR, Chia J, Jarvis WR. Candida albicans endocarditis associated with a contaminated aortic valve allograft: implications for regulation of allograft processing. Clin Infec Dis. 1998;27:688-91.

17. Centers for disease control, prevention. Notice to readers: FDA rule for current good tissue practice for human cells, tissues, and cellular and tissue-based products. MMWR Morb Mortal Wkly Rep. 2005;54:490.

18. Centers for disease control, prevention. Update: Creutzfeldt-Jakob disease in a patient receiving a cadaveric dura mater graft. MMWR Morb Mortal Wkly Rep. 1987;36:324-5.

19. The Canadian Neurosurgical Society Recommendations: Tutoplast Dura Mater. 2003; Available from: http://www.hc-sc.gc.ca/dhp$\mathrm{mps} /$ medeff/advisories-avis/prof/2002/ tutogen_nth-ah_e.html. 